\title{
Analysis of vibration signals produced by the cavitation in centrifugal pumps using the Power Spectrum and Continuous Wavelet Transform
}

\section{Análise de sinais de vibração produzidos por cavitação em bombas centrífugas usando o Espectro de Potência e a Transformada de Wavelet Contínua}

\author{
Tobias Anderson Guimarães ${ }^{\star 1}$; Ricardo Humberto de Oliveira Filho*2 \\ *Professor do Departamento de Engenharia Mecânica, Universidade Federal do Triângulo Mineiro, Uberaba, \\ Minas Gerais, Brasil. \\ 1Orcid: https://orcid.org/0000-0002-6350-7867. E-mail: tobias.guimaraes@uftm.edu.br \\ 2Orcid: https://orcid.org/0000-0002-6077-9410. E-mail:rhofilho@gmail.com
}

\begin{abstract}
The cavitation phenomena cause noise, vibration and instability in centrifugal pumps. Furthermore, the cavitation usually generates wear and material erosion of the rotor blades which decreases the hydraulic performance and the pump life. In this work, it will be studied the vibration components produced by the centrifugal pumps cavitation using the signal processing and statistical analysis. For this purpose, the vibration signals were measured in three directions, $x, y$ and $z$ using accelerometers near to the rolling bearing of the pump with and without cavitation. In this way, an analysis of the power spectrum was applied in order to identify which direction would be more sensitive to the presence of the cavitation in the pump. Subsequently, the Continuous Wavelet Transform was applied to the vibration signals in the time domain for analyzing the vibration components caused by the cavitation. The results proved that this methodology can serve as a tool of analysis and identification of vibration components caused by the cavitation in centrifugal pumps.
\end{abstract}

Keywords: cavitation, centrifugal pumps, vibration signals, time-frequency analysis.

RESUMO: O fenômeno de cavitação provoca ruído, vibrações e instabilidade em bombas centrífugas. Além disto, a cavitação normalmente gera desgaste e erosão do material das pás do rotor o que diminui o rendimento hidráulico e a vida útil da bomba. Neste trabalho será estudado as componentes de vibração produzidas pela cavitação em bombas centrífugas usando processamento de sinais e análise estatística. Para este propósito, inicialmente foi realizada uma medição dos sinais de vibração em três direções, $x$, y e $z$ usando acelerômetros localizados próximos aos mancais de rolamentos da bomba com e sem cavitação. Desta forma, uma análise do espectro de frequências foi aplicada a fim de se identificar qual direção seria mais sensível a presença da cavitação na bomba. Posteriormente foi aplicada a Transformada de Wavelet Contínua aos sinais medidos para avaliar os possíveis componentes de vibração provocados pela cavitação na bomba centrífuga. Os resultados comprovam que a metodologia proposta pode servir como uma ferramenta de análise e identificação dos componentes de vibração provocados pela cavitação em bombas centrífugas.

Palavras-chave: análise tempo-frequência, bombas centrífugas, cavitação, sinais de vibração. 


\section{INTRODUCTION}

Cavitation phenomena in centrifugal pumps generate instability and decrease their hydraulic performance. The cavitation also causes others undesired effects in centrifugal pumps, such as, pitting, material erosion of the rotor blades, vibration and noise (CUDINA, 2003; SAKTHIVEL et al., 2010). During the cavitation process, the fluid starts to flash and vaporization occurs. In this way, the pump walls and the rotor blades are bombarded by the bubbles due to the vaporization. This process of the bombardment of the bubbles on the pump components produces random vibrations with frequencies to be determined in the spectrum of measured signals. Hence, the application of the signal analysis techniques in the diagnosis of cavitation in pumps is an important tool to be used in the correction of their ideal operation range.

In the condition monitoring of the pumps, it is usually used vibration signals or acoustic signals in order to detect the cavitation phenomena. For example, Cudina (2003) used acoustic signals to identify the beginning of cavitation of centrifugal pumps of a nuclear power plant. Subsequently, Cernetic, Prezelj e Cudina (2008) has applied the Fourier Transform to the noise and vibration signals measured in the kinetic pumps with microphones and accelerometers for monitoring the cavitation phenomena. Sakthivel et al. (2010) have developed a pump faults classification system using the measured vibration signals with accelerometers and the logic fuzzy for the automatic identification of the cavitation, bearing fault, seal and impeller faults. In this system, the classification fuzzy rules and membership functions were created using the statistical parameters extracted from vibration signals. Zhang et al. (2014) have investigated the vibration characteristics of centrifugal pumps by the measuring of the signals with several accelerometers placed on the pump. Hence, they analyzed the vibration signals in three directions by means of the Root Mean Square Method or vibration energy due to the pump cavitation. Ramadevi (2014) applied the Discrete Wavelet Transform for the detection of the vibration signals produced by the cavitation in pumps. The aim of this study was to extract the characteristics of the transient vibration components generated by the pump with cavitation.

In this work, it will be studied the transient vibration signals caused by the cavitation in centrifugal pumps of the water treatment plant using the Continuous Wavelet Transform. The main objective is to purpose a methodology and a signal processing tool in order to analyze the random patterns produced by the cavitation phenomena in centrifugal pumps. First of all, the vibration signals were measured using three accelerometers placed near to the rolling bearing from pump. The vibration signals were measured in three directions in order to identify which direction would be more sensitive to the presence of the cavitation. After measuring of the centrifugal pump vibration without and with cavitation, the signals in the time domain will be processed to the time-scale domain using the Continuous Wavelet Transform (CWT). Subsequently, the random vibration energy density will be obtained using the statistical parameters, such as, mean and standard deviation (COHEN, 1995). By using this methodology, it is possible to separate the vibration signals components caused by the cavitation from the noise spectra and to analyze the presence of this undesired vibration source in centrifugal pumps. 


\section{CAVITATION IN CENTRIFUGAL PUMPS}

\section{Description of the phenomena}

A centrifugal pump is a hydraulic machine that transforms work from drive motor into the mechanical energy of the flowing liquid. The main components of a centrifugal pump are the rotor shaft, the blades, the pump wall and the bearings. In hydraulic systems, cavitation naturally occurs due to the acceleration of the fluid caused by the transformation of the rotor blades work in fluid kinetic energy. According to the mechanic energy conservation principle, when the liquid is accelerated its pressure diminished. Since the absolute static pressure of fluid is lower the saturated vapour pressure in some points of the flow, at the prevailing temperature conditions, the fluid starts to flash and vaporization occurs (CUDINA, 2003). Because of this, bubbles are caught up by the flowing liquid which causes the collapse of these on the rotor blades and on the centrifugal pump wall. Usually, the collapse time of the bubbles implosion is very small (approximately $0,003 \mathrm{~s}$ ) which increases the bubbles impact pressure on the centrifugal pump components.

In practice, the cavitation could be interpreted as the bombardment of the bubbles on the rotor blades and centrifugal pump walls. Figure 1 illustrates an example of the damages caused by the cavitation phenomena in rotor blades of a centrifugal pump. Since the bombardment frequency of the bubbles and its intensity (amplitude) is not defined, it is difficult to predict analytically the features of the vibration signals produced by the cavitation in centrifugal pumps.

Figure 1. Centrifugal pump rotor damage by cavitation

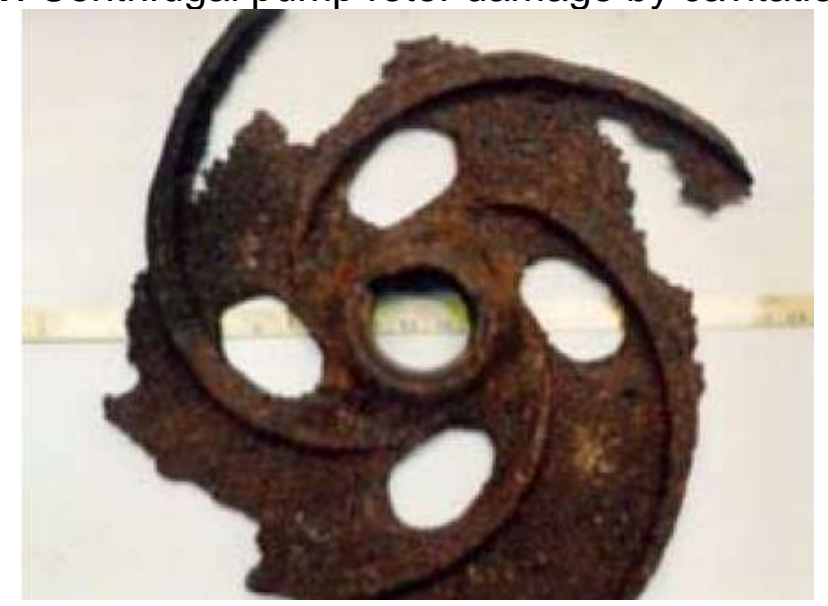

Source: Oliveira, 2018.

\section{Characteristics of the vibration signals measured in centrifugal pumps}

In general each pump component generates a vibration signal component with a determined frequency. For example, the vibration frequency of the rotor shaft is the rotation frequency of the centrifugal pump working. The vibration signals components produced by the rotor blades have a frequency which is obtained by multiplying the number of blades by the rotational frequency of the rotor shaft. On the other hand, the vibration caused by the rolling bearings from rotor is similar to the vibration of a single-degree-of-freedom mechanical system which excites the high frequencies range of the spectra. All these vibration components abovementioned are deterministic and could be easily detected by 
analyzing the frequency spectrum of the measured signals in the centrifugal pumps (SAKTHIVEL et al, 2010).

Identification of the vibration frequencies caused by the cavitation in centrifugal pumps is more difficult by using the signal frequency spectrum. For the cavitation, the frequency of the bombardment of the bubbles on the rotor blades which has the character water hammer blows could be not determined analytically (CUDINA, 2003). Thus, it is easier to detect the frequency range of vibration produced by the cavitation due to the random nature of these signals. For the velocity signals, the frequency range of the cavitation vibration is placed on low frequency range of the spectrum. In the case of the acceleration signals, the cavitation excites the high frequencies range of the measured vibration signals. In this work, it will be used the Continuous Wavelet Transform and statistical techniques in order to extract the energy density of these random vibration components.

\section{TOOLS FOR THE VIBRATION SIGNALS ANALYSIS MEASURED IN THE CENTRIFUGAL PUMP}

\section{Continuous Wavelet Transform}

The Fourier Transform (FT) and the Continuous Wavelet Transform (CWT) could be defined using the correlation concept of the signal. In the traditional spectral analysis, the vibration signal in the time domain is compared with harmonic functions. In this way, by using the Fourier Transform (FT), the vibration signal could be decomposed in the individual frequency components. Although the FT is a powerful tool in the signal processing context, its main disadvantage is that the transient vibration signals caused by the cavitation in pumps could not be easily extracted by the conventional spectral analysis. Since that the window in the time domain used in the FT has infinity duration, it is not possible to extract neither when the transient component has occurred and nor its duration in the timefrequency plane (COHEN, 1995). In this case, appropriate techniques of the non-stationary signal analysis should be used for this purpose.

In the CWT, a correlation between the vibration signal, $\mathrm{x}(\mathrm{T})$ and functions previously chosen by the signal analyst, known as mother wavelet, is computed during its processing In this work, it will be applied the Continuous Wavelet Transform (CWT) to the vibration signals measured in the centrifugal pumps with and without cavitation. The main advantage of the CWT when compared the Short Time Fourier Transform (STFT) is the multiresolution analysis used in the decomposition of the vibration signal. For the vibration components with high frequency is used a mother wavelet with short duration; otherwise, for the signal components with low frequency, the mother wavelet used in the analysis has long time duration. The CWT to be used in this work is defined by (HENEGHAN et al., 1994):

$\operatorname{CWT}(t, a)=\frac{1}{\sqrt{a}} \int x(\tau) \varphi^{*}(t-\tau) d \tau$

Where $\varphi$ is the mother wavelet which is compared with signal in the time domain, $x(\tau)$, $a$ is a scale factor used in the dilation of $\varphi(t)$ and $t$ is the delay time used in the convolution integral from CWT. In practice, there exist different types of mother wavelet that can be used in the correlation with $x(t)$. In this work, it will be used the Morlet Wavelet for the extraction of the features of transient vibration produced by cavitation in centrifugal pumps. Indeed, the Morlet Wavelet is an amplitude modulated harmonic function with a Gaussian envelope. For 
the Morlet Wavelet, the central frequency of the band of $\varphi(t)$ can be easily associated with the scale factor used in its dilation.

Figure 2 shows the Morlet wavelet used in the CWT of the vibration signals to be measured in the centrifugal pumps. The relation between the scale and frequency, $f$, of Morlet wavelet family correlated with the vibration signals is described by Eq. (2) (HENEGHAN et al., 1994):

$a=\log _{2}\left(\frac{k_{\varphi}}{f}\right)$

Where the parameter $V$ represents scale division and $k_{\varphi}$ a constant to be determined. In this work, this equation will be used to estimate the frequencies of the transient vibration components due to the pump cavitation. Equation (2) shows that the larger is the scale factor, the lower is the frequency of the components of signal, the larger is the dilation of the mother wavelet.

Figure 2. Morlet wavelet applied in vibration signals analysis

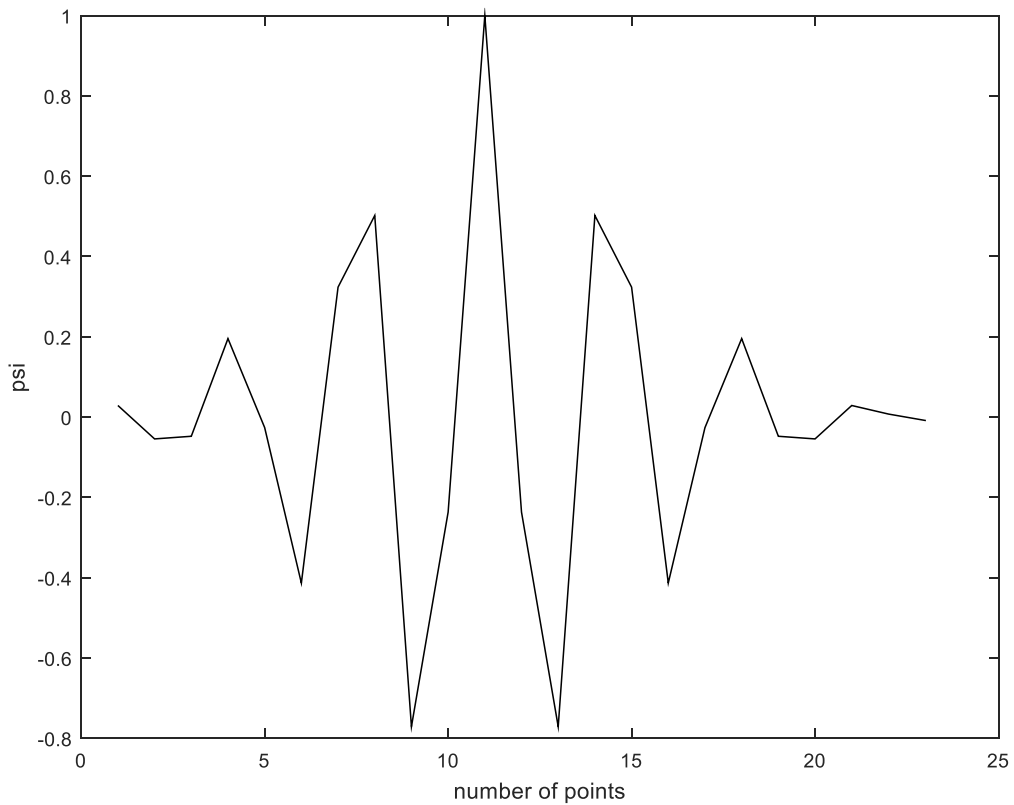

\section{Estimation of the Duration of the Transient Vibration Components Caused by the Pump Cavitation}

The duration of the transient components of the vibration signal measured in the centrifugal pump can be estimated by standard deviation concept in the time domain. A simple way of calculation this parameter is to use the energy density of the signal per unit time or instantaneous power, $|x(t)|^{2}$. However, as the average process is applied to the vibration in the time domain, this parameter represents only the global mean duration of the full signal. The global mean time and global mean duration of the signal are defined respectively by (COHEN, 1995):

$\left\langle t>=\frac{1}{k(t)^{2}} \int t x(t)^{2} d t\right.$ 


$$
\sigma_{t}^{2}=\frac{1}{\left|x(t)^{2}\right|} \int(t-<t>)^{2}|x(t)|^{2} d t
$$

Unfortunately, the mean duration of the transient vibration components caused by the cavitation could not be estimated using the Eq. (4). The standard deviation in Eq. (4) is the global spread of signal in the time domain and can not represent the duration of the vibration components due the cavitation. Nevertheless, it is possible to extract several parameters to be used in the study of the pump cavitation, as for example, the average duration of the transient vibration components or the frequency band excited by these components by using the CWT given in the Eq. (1) (COHEN, 1995; LOUGHLIN; CAKRAK; COHEN, 2000). These quantities are known as local averages (COHEN, 1995). In this work, it will be estimated the conditional mean duration, $\sigma^{2} t \mid \omega$, of the transient vibration components caused by the cavitation according to the equation (5) (COHEN, 1995):

$$
\sigma_{t \mid \omega}^{2}=\frac{1}{P(\omega)} \int\left(t-\langle t\rangle_{\omega}\right)^{2} P(t, \omega) d t
$$

Where $P(\omega)$ represents the signal magnitude in the frequency domain, $\omega$, and $P(t, \omega)$ is the joint time-frequency probability density function. The parameter $\langle t\rangle \omega$ is the conditional average time of the transient components given by (COHEN, 1995)

$$
\langle t\rangle_{\omega}=\frac{1}{P(\omega)} \int t P(t, \omega) d t
$$

That is, the local mean time of the vibration signal calculated for the selected frequency, $\omega$. In this work, the joint time-frequency probability density function to be used in the calculation of the mean duration of the transient components will be the CWT defined by the Eq. (1). This parameter may be correlated to the vibration caused by the collapse time of the bubbles generated by the cavitation.

\section{MEASURING AND PROCESSING OF THE VIBRATION SIGNALS}

For the measuring of vibration data, it was used 3 (three) accelerometers mounted on the cube faces with $1 \mathrm{~cm}^{3}$ of volume, which measure the acceleration vibration signals simultaneously in axes $x, y$ and $z$. Figure 3 illustrates the centrifugal pump used for the measuring and analysis of vibration signals with and without cavitation. During the measuring, the 3 accelerometers were placed on the pump case as close as possible from the rolling bearings. To investigate the effect of cavitation, were measured 2 (two) centrifugal pumps from the same manufacturer and model, one without cavitation and other with cavitation operating under the same conditions. The 3 accelerometers were positioned in each axes, $x, y$ and $z$. In each measuring, it was obtained only one sample of the signal in the time domain with the parameters described in the Table 1.

The vibration signals were measured by using 3 accelerometers from $\mathrm{PCl}$ manufacturer model 352C33. Table 1 describes the parameters values used for measuring the vibration data in the time domain. The signals measured from centrifugal pump without and with cavitation were directly connected to a data acquisition board from National Instruments model NI 9234. Subsequently, the software Matlab ${ }^{\circledR} 2009$ with a toolbox integrated to the software Labview ${ }^{\circledR}$ was used to save the data file in a txt format. 
Revista Brasileira de Ciência, Tecnologia e Inovação

Figure 3. Centrifugal pump image with cavitation - Vale Group, Uberaba Unit

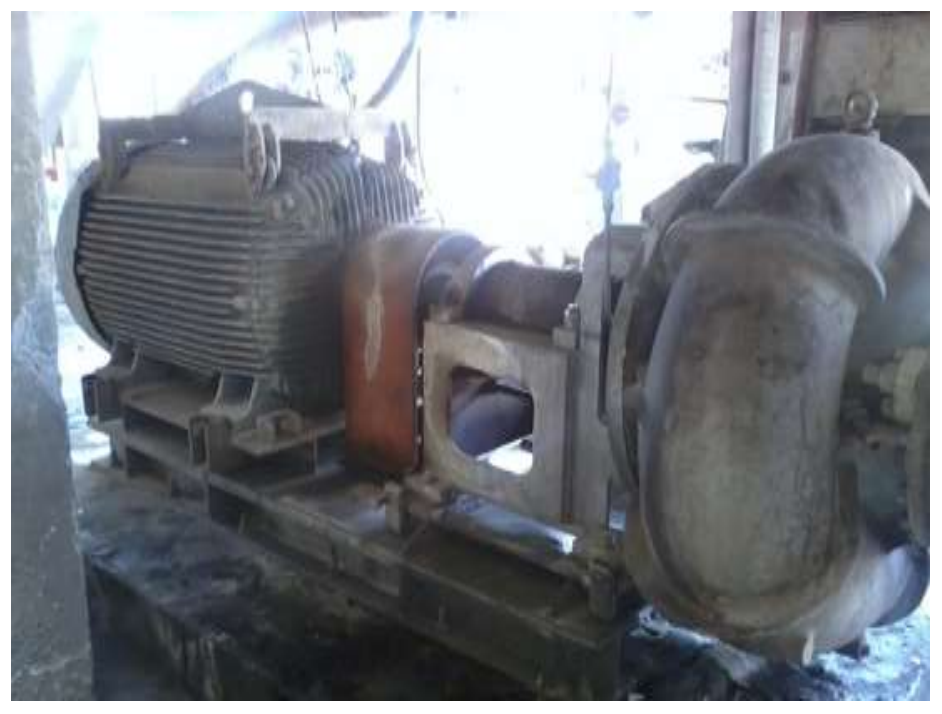

Table 1. Parameters values used in the acquisition of vibration signals

\begin{tabular}{cccc}
\hline Sampling Frequency & Number of Points & Acquisition Time & $\begin{array}{c}\text { Sensitivity of } \\
\text { Accelerometer }\end{array}$ \\
\hline $25600 \mathrm{~Hz}$ & 100000 & $3.9 \mathrm{~s}$ & $1.05 \mathrm{mV} / \mathrm{m} / \mathrm{s}^{2}$ \\
\hline
\end{tabular}

After the vibration data aquisition, the signals in the time domain were processed to the frequency domain using the FFT (Fast Fourier Transform) algorithm available in the Matlab ${ }^{\circledR}$ R2009 software. This spectral analysis was necessary to determine the is frequency range of the stochastic vibration components produced by the pump cavitation. The sampling frequency of $25600 \mathrm{~Hz}$ was applied in the signal processing to analyze the frequency components caused by the cavitation up to $12800 \mathrm{~Hz}$ according to the Nyquist theorem. In Matlab ${ }^{\circledR}$, the CWT time scale matrix was determined by Eqs. (1) and (2). A parameter $\mathrm{V}$ equals to 12 division of scale was used for wavelets frequency.

\section{ANALYSIS OF THE RESULTS}

The Figure 4 illustrates the vibration signals in the time domain measured in the centrifugal pump without and with cavitation in three directions, $x, y$ and $z$. The signals on the left side represents the pump vibration without cavitation and on the right side corresponds the pump vibration with cavitation. The amplitude vibration of the signal measured in the pump with cavitation is larger than the amplitude vibration of pump without cavitation. For the pump without cavitation, the root mean square $(\mathrm{rms})$ is equal to $3.56 \mathrm{mV}$, $6.62 \mathrm{mV}$ and $3.65 \mathrm{mV}$ with respect to axis $\mathrm{x}, \mathrm{y}$ and $\mathrm{z}$ respectively. Else, the rms for the pump with cavitation is $6.97 \mathrm{mV}(95 \%), 11.48 \mathrm{mV}(73 \%)$ and $5.00 \mathrm{mV}(36 \%)$ with respect to axis $\mathrm{x}, \mathrm{y}$ and $\mathrm{z}$ respectively. The $\mathrm{x}, \mathrm{y}$ and $\mathrm{z}$ direction vibration signal energy show that the axis $\mathrm{x}$ was more sensitive to the vibrations caused by the pump cavitation.

The Power Spectrum of the vibration signals measured in the centrifugal pump with and without cavitation are shown in the Figure 5. In this analysis, the amplitude of the signals in the frequency domain represents the Power Spectrum in order to compare the energy associated with each frequency band. The signals measured in the pump without (left) 
cavitation are represented in yellow color and the signals from pump with (right) cavitation in red color. Moreover, for normal conditions operation, the vibration energy is smaller than the vibration energy for cavitation on high frequencies. Based on the Figure 5, this energy difference in the frequency domain in three direction is most notable in medium frequencies (about 2000 to $4000 \mathrm{~Hz}$ ) for axis $\mathrm{x}$.

Figure 4. Vibration signals in the time domain measured in the centrifugal pump without and with cavitation
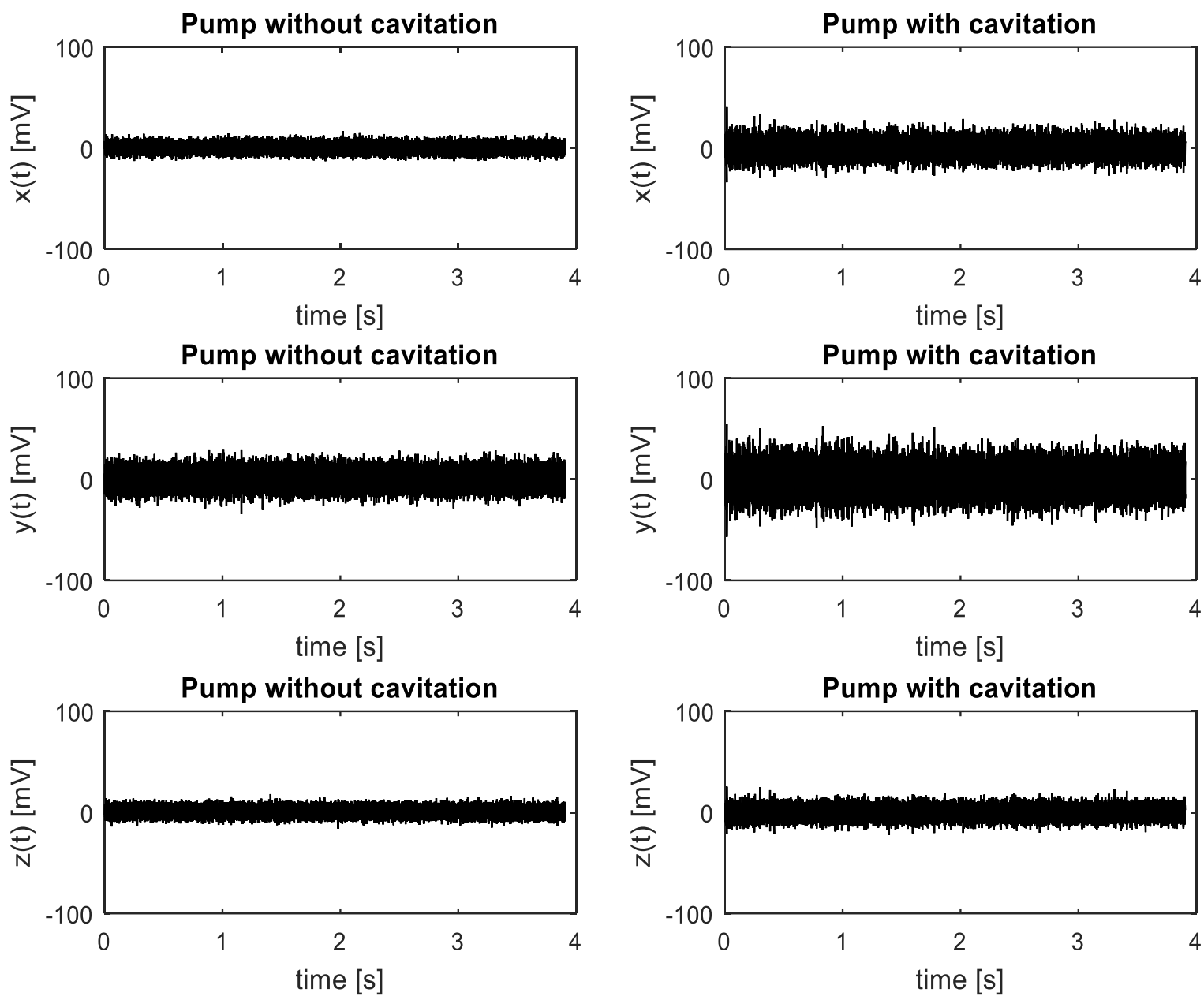

Figure 6 shows the signal amplitude for the $x$ direction up to $4000 \mathrm{~Hz}$. In this figure, the signal amplitude unit for centrifugal pump without (yellow) and with (red) cavitation is defined in $\mathrm{mV}^{2}$. An amplitude on $78 \mathrm{~Hz}$ and his harmonic is correlated to pump operation frequency on $4860 \mathrm{rpm}$. Also, the $1232 \mathrm{~Hz}$ component observed on both spectrum (without and with cavitation) probably is resulted by blades number multiplied by the operation frequency. Furthermore, there are vibration components related to electrical motor, rolling bearing and other pump elements, which to the Spectrum displayed in the Figure 6. 
Figure 5. Vibration signals in the frequency domain measured in the centrifugal pump without and with cavitation
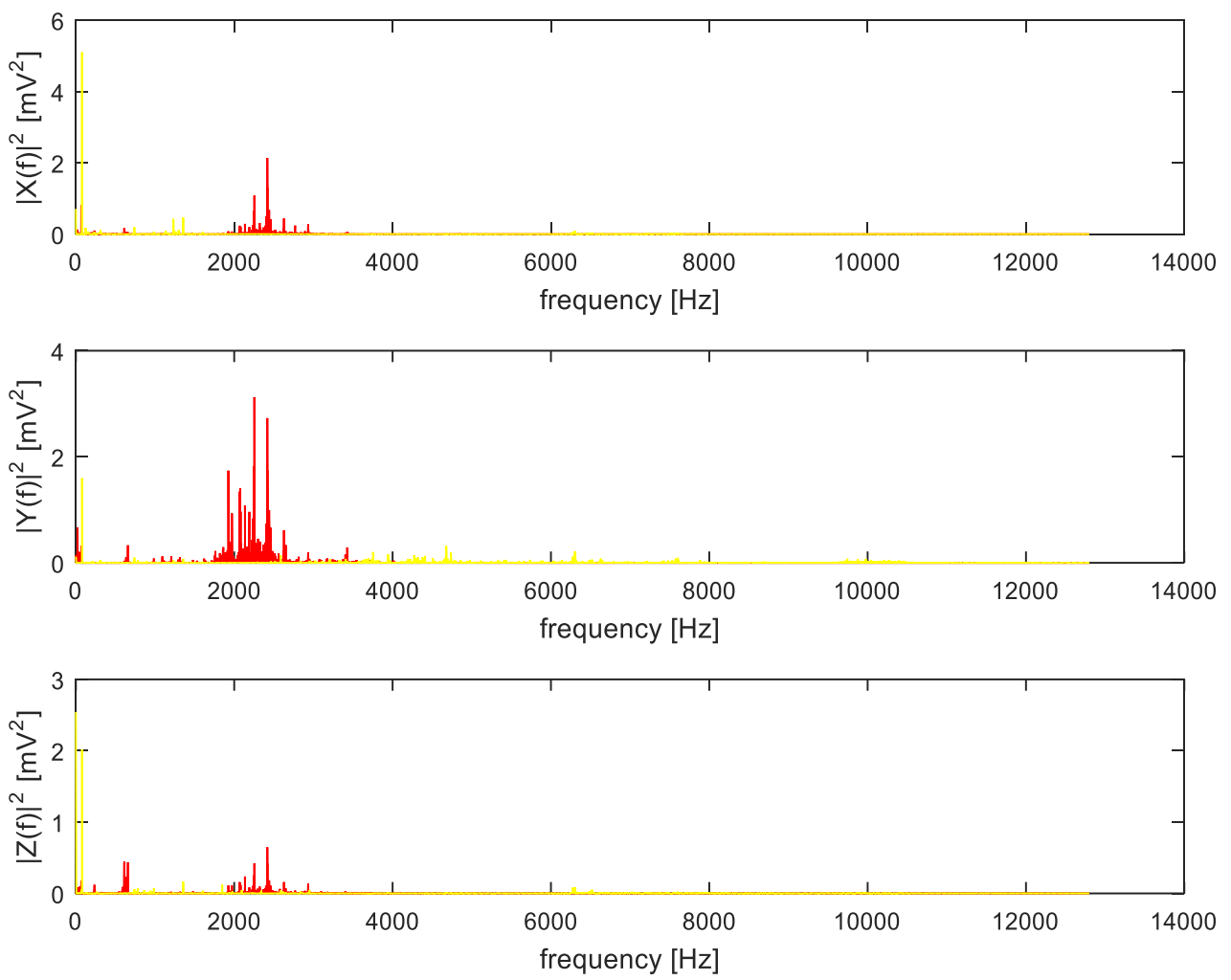

Figure 6. Power Spectrum of the vibration signal measured in the direction $\mathrm{x}$ for the pump without and with cavitation
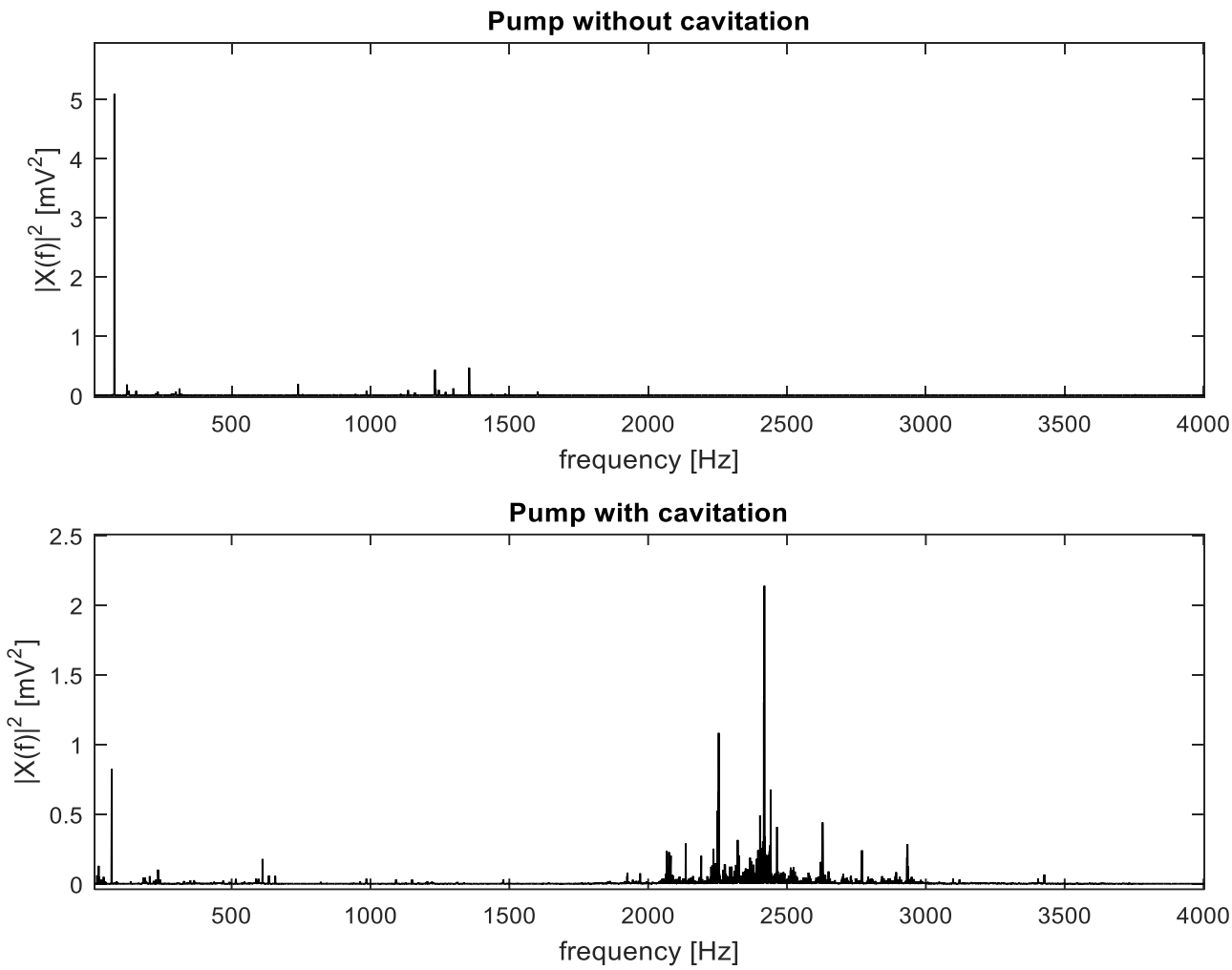
After the signal analysis in the frequency domain, the vibration signals measured in the pump in the direction $\mathrm{x}$ were processed for the wavelet domain, as can be seen in Figure 7. For the vibration processing using the Continuous Wavelet Transform (CWT), it was considered 100000 samples of the time domain signal. Before the signal frequency components calculation by the CWT, the constant $\mathrm{k}$ on Eq. (2) was estimated by a known $5000 \mathrm{~Hz}$ frequency component. Thereby, the CWT can be applied to vibration signal analysis of the pump without and with cavitation, the maximum frequency is limited to 7500 $\mathrm{Hz}$ according to the estimated constant $\mathrm{k}$.

The scalogram for pump without cavitation presents a strong component in scale 78 (low frequencies), due to operation frequency. Also, there are less energic components in medium frequencies (scales 50 to 60) and high frequencies (scales 0 to 20). Furthermore, it can be also seen several components of the vibration in the range of scales of 78 to 100 (region of low frequencies). These components were generated by the noise and by the pump vibration in its rotation frequency. On the other hand, the scalogram for pump with cavitation shows two components nearby scale of 20 and 80 to 100 related to cavitation, also the operation frequency component is present in scale 78, but with inferior energy than cavitation effect.

The Figure 8 illustrates the conditional mean time and the conditional standard deviation of the vibration signal measured in the centrifugal pump with cavitation. In the scale of 20 , the mean duration of the signal is approximately $0.01 \mathrm{~s}$. This value represents the mean duration of the vibration transient components caused by the cavitation, as shown in Figure 7. In fact, observing the CWT in the Figure 7, it can be seen the component duration of $0.01 \mathrm{~s}$ at scale 20 . In the scale of 80 (region of low frequency) the local duration of this component is about $0.007 \mathrm{~s}$. The periodicity of this vibration component is associated to the amplitude modulation phenomena due to rotor pump rotation frequency.

Figure 7. CWT of the vibration signal measured in the direction $\mathrm{x}$ in the centrifugal pumps without and with cavitation
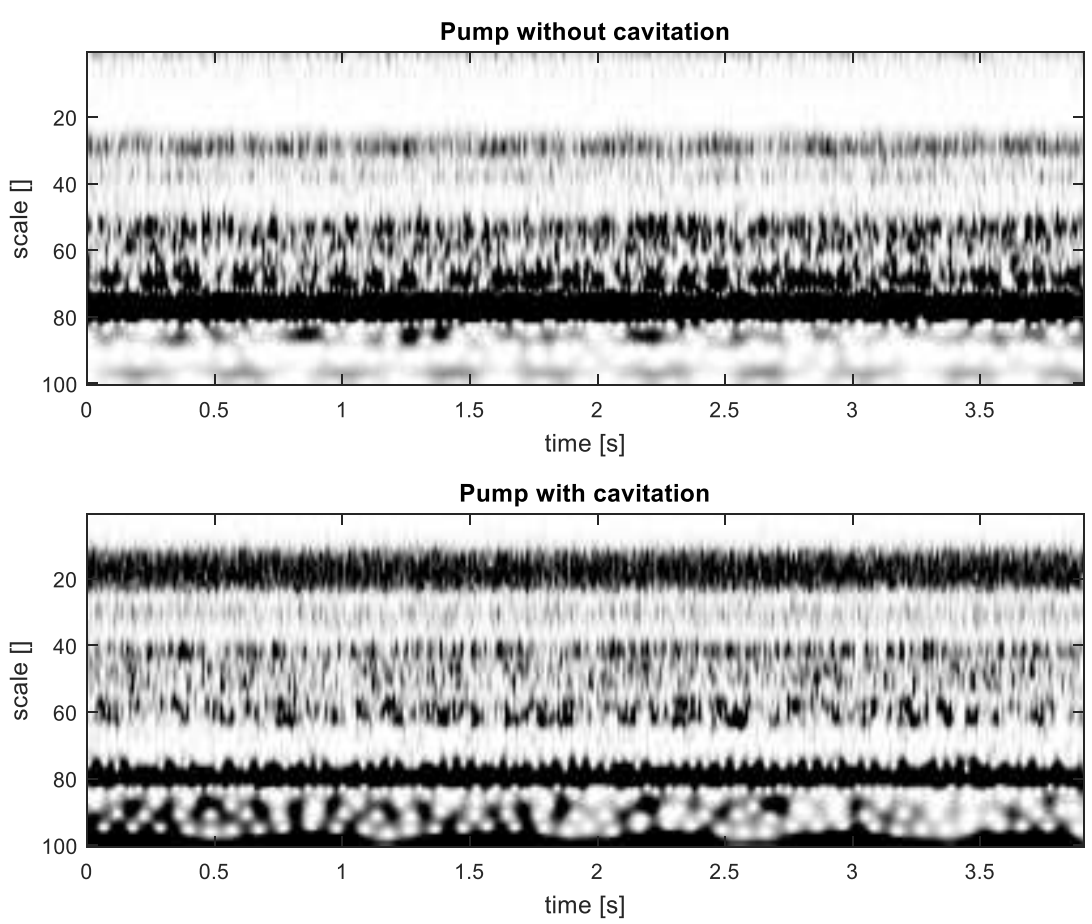
Figure 8. Conditional average time and conditional mean duration of the pump vibration signal with cavitation
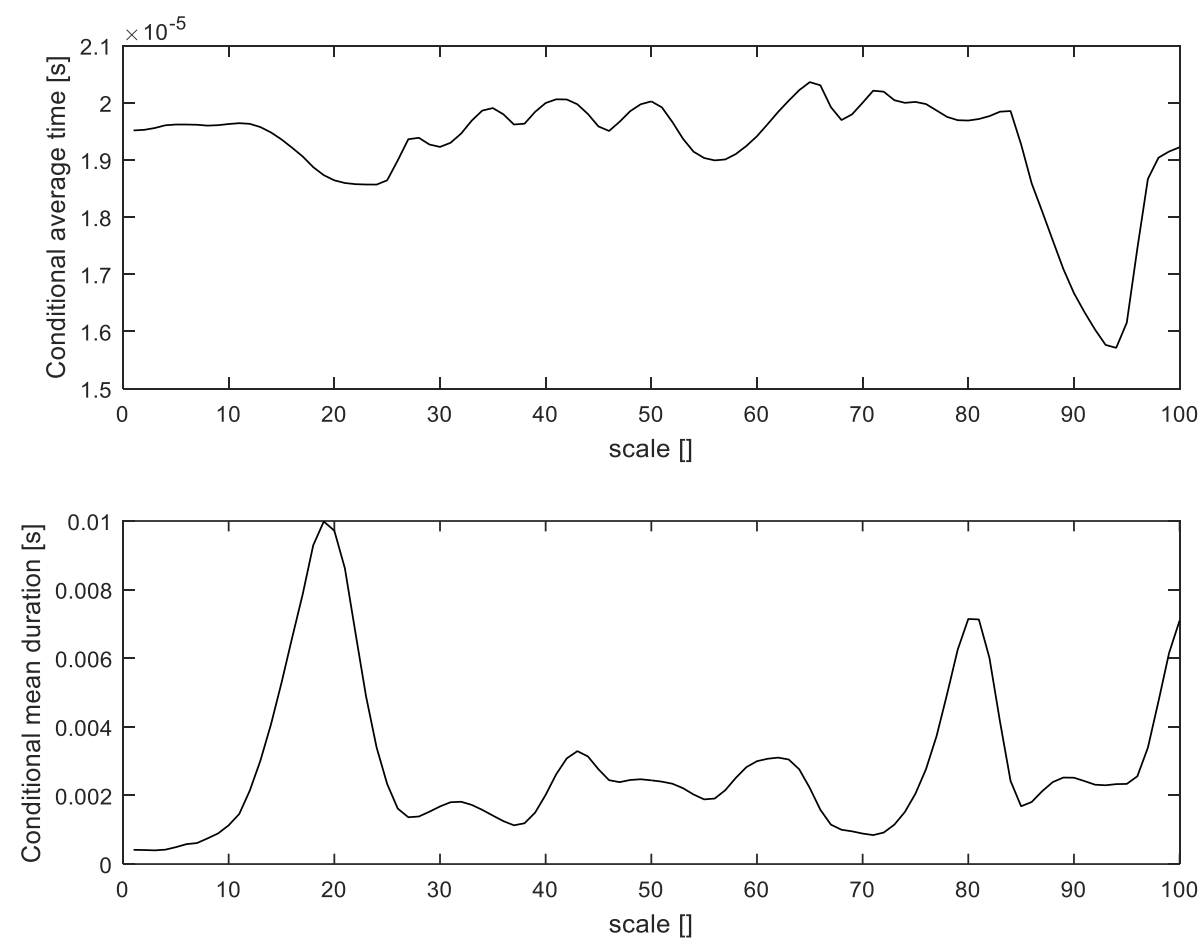

\section{CONCLUSIONS}

In this work, it was used the spectral and wavelet analysis applied to the vibration signals measured in centrifugal pumps in order to detect the cavitation phenomena. First of all, the vibration signals were measured on the pump case using the accelerometers. In the next step, the vibration signals in the time domain were processed to the frequency and wavelet domains, applying the Fast Fourier Transform and the Continuous Wavelet Transform. The spectral analysis was necessary to identify frequency band of vibration signals components produced by the cavitation effect. On the other hand, the Continuous Wavelet Transform was applied to the vibration data to extract the features of the signal transient components generated by the pump cavitation. From a machinery monitoring point of view, these results can help to analyze the cavitation phenomena in centrifugal pumps.

Subsequently, the CWT was used as a joint time-scale probability density function in order to estimate the local mean time and local duration of the transient vibration components caused by the cavitation. These values of these parameters were compared with the transient vibration data presents in CWT scalogram. In this context, these parameters could indicate the presence of faults in centrifugal pumps.

\section{ACKNOWLEDGEMENTS}

The authors would like to acknowledge the VALE Group, Uberaba Unit, for allow the measuring of the vibration signals in the centrifugal pumps of its industrial plant. Furthermore, the authors would like to acknowledge the FAPEMIG (Fundação de Amparo à Pesquisa do Estado de Minas Gerais) by the financial support. 


\section{REFERENCES}

CERNETIC, J.; PREZELJ, J.; CUDINA, M. Use of Noise and Vibration Signal for Detecting and Monitoring of Cavitation in Kinetic Pumps. In: Proceedings of Acoustics 08 Paris, Euronoise, p. 2199 - 2204, 2008.

COHEN, L. Time-Frequency Analysis. 1. ed. New Jersey: Prentice Hall, 1995.

CUDINA, M. Detection of the Cavitation Phenomena in a Centrifugal Pump Using Audible Sound. Mechanical Systems and Signal Processing, v. 17, n. 6, p.1335 - 1347, 2003.

HENEGHAN, C.; KHANNA, S. N.; FLOCK, A.; ULFENDAHL, M.; BRUNDIN, L.; TEICH, M. C. Investigating the Nonlinear Dynamics of Cellular Motion in the Inner Ear Using the Short Time Fourier Transform and Continuous Wavelet Transform. IEEE Transactions on

Signal Processing, v. 12, n. 12, p. 3335 - 3353, 1994.

LOUGHLIN, P.; CAKRAK, F.; COHEN, L. Conditional Moments Analysis of Transient with Application to Helicopter Fault Data. Mechanical Systems and Signal Processing, v. 14, n. 4, p. $511-522,2000$.

OLIVEIRA, R. J. Cavitação: como entender este fenômeno? Disponível em:

http://mgstecnologia.com.br/noticias/admin/arquivos/Cavitacao.pdf. Acesso em: 24 nov. 2018.

RAMADEVI, R. Classification of Vibration Signal to Detect Pump Cavitation Using Discrete Wavelet Transform. International Journal of Computer Applications, v. 93, n. 10, p. 36 - 39, 2014.

SAKTHIVEL, N. R.; SUGUMARAN, V.; NAIR, B. B. Comparision of Decision Tree-Fuzzy and Rough Set Fuzzy Methods for Fault Categorization of Mono-Block Centrifugal Pump. Mechanical Systems and Signal Processing, v. 24, p. 1887 - 1906, 2010.

ZHANG, N.; YANG, M.; GAO, B.; LI, Z. Investigation of Vibration Characteristics in a Centrifugal Pump with Special Slope Volute. Advances in Mechanical Engineering, v. 7, n. 2, p. $1-14,2014$. 